\title{
John Chassar Moir (1900-1977) and the discovery of ergometrine
}

\section{P M Dunn}

Arch Dis Child Fetal Neonatal Ed 2002;87:F152-F154

Chassar Moir led the research in the early 1930s that resulted in the discovery and identification of ergometrine, the active water soluble component of ergot of rye. Its use in preventing and controlling postpartum haemorrhage has saved countless lives in the years since. As professor of obstetrics and gynaecology in Oxford, he achieved distinction for his repair of vesicovaginal fistulae.

Correspondence to:

Professor Dunn

Department of 'Child

Health, University of Bristol,

Southmead Hospital,

Southmead, Bristol

BS 10 5NB, UK;

p.m.dunn@bristol.ac.uk

Accepted 2 April 2002

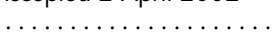

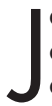

ohn Chassar Moir was born in $1900 .^{1{ }^{2}}$ His parents lived in Montrose where he received his education at the Montrose Academy. Thereafter he studied at the University of Edinburgh where he qualified in medicine in 1922. He also studied in Vienna and Berlin, and later at the Johns Hopkins Hospital, Baltimore. After graduation he first went into general practice before obtaining the FRCS Ed and becoming assistant surgeon to the East Surrey Hospital. In 1930 he submitted a thesis on "Internal rotation" to his alma mater, Edinburgh University. For this he was awarded a gold medal and promoted MD. The same year he was appointed as first assistant to Professor F J Browne at University College Hospital, London. During the next five years he obtained the MRCOG and undertook research which led to the discovery of ergometrine. In 1935 he was appointed reader in obstetrics and gynaecology in the University of London at the new British Postgraduate Medical School in Hammersmith, a post he held for the following two years (fig 1).

\section{THE DISCOVERY OF ERGOMETRINE}

It had been known since the 16th century that ergot of rye was capable of inducing strong uterine contractions. In 1808 Dr John Stearns of the State of New York wrote: "You will be surprized by the suddenness of its operation; it is therefore necessary to be completely ready before you give the medicine". However the effects of "pulvis parturiens" were so unpredictable and variable that by the 20th century it was relatively little used in clinical practice except to promote postpartum involution of the uterus.

In 1906 and 1918, two active alkaloids of ergot, ergotoxine and ergotamine, had been isolated in pure state. Although not submitted to adequate clinical trials, it was assumed that they were responsible for the "oxytocic effect" of ergot. In 1932 Moir showed this assumption to be incorrect. Working at University College Hospital, and encouraged by F J Browne and Sir Henry Dale, he used a technique first described by Schatz in 1872 for measuring the oxytocic effect of the drugs by placing, with strict aseptic precautions, a small fluid filled balloon within the uterus on the 7th day post partum. ${ }^{3}$ He reported that both ergotoxine and ergotamine were sparingly soluble in water and, while capable of causing uterine contractions, they were both slow to act especially when given by mouth. Once absorbed, however, the effect was persistent and might cause toxic symptoms such as gangrene. In contrast, he found the action of aqueous extract of ergot to be very different. He wrote ${ }^{3}$ :

\begin{abstract}
"Judged by all previous work this preparation ought to have been inert, for analysis showed that it contained only a trace of alkaloid. . . It was with the greatest surprise I found that, far from being inert, this preparation surpassed by great measure the activity of any drug which I had previously used in the same manner. An equally surprising fact was that the effect appeared in a remarkably short time. In one case only four minutes elapsed between the swallowing of the extract and the onset of powerful uterine contractions
\end{abstract}

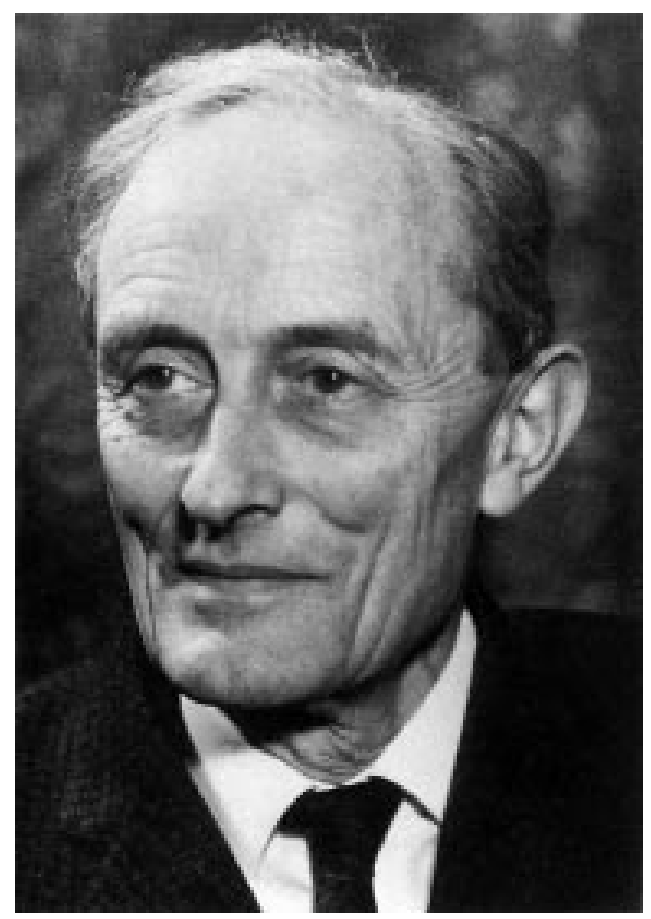

Figure 1 John Chassar Moir (1900-1977). 

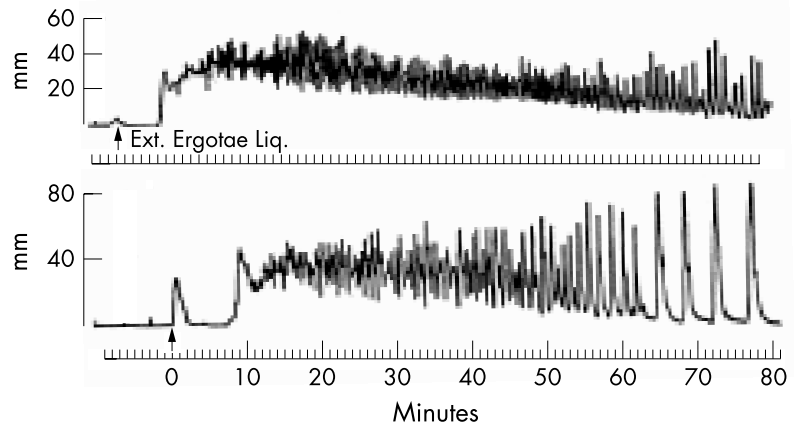

Figure 2 Top: the tracing that first showed on 11 March 1932 the presence of an unidentified active principle in crude ergot. Bottom: the first tracing made on 9 February 1935 with the purified alkaloid, later to be named ergometrine.

(fig 2). In character the contractions were notably different from those due to ergotoxine or ergotamine. They were frequent (two or three to the minute), regular, of fairly great excursion, and there was a rise in the base line to an extent much greater than observed with any other drug."

The hunt was now on to isolate the active principle. Sir Henry Dale asked his chief research chemist, Dr Harold Ward Dudley (1887-1935) to take on the task. Eventually success was achieved on 9 February 1935 and reported in the BMJ on 16 March 1935 (fig 2, bottom). Sir Henry Dale suggested that the new alkaloid should be called ergometrine. The method of preparation was published in full without patent rights or proprietary interests so that it would be free for any manufacturing firm to produce and market. Sadly, on the very day of publication, Dr Dudley died prematurely at the age of 49 years. ${ }^{4}$

The following year Moir wrote ${ }^{5}$ :

"Ergometrine has the formula $\mathrm{C}_{19} \mathrm{H}_{23} \mathrm{O}_{2} \mathrm{~N}_{3}$; the molecule is therefore much smaller than that of the ergot alkaloids previously known. It is remarkable for the rapidity with which it is absorbed from the alimentary canal, a feature clearly differentiating it from the other ergot alkaloids. It is also reasonably stable, is resistant to boiling, and keeps well in crude ergot extracts ... It is highly active in promoting contractions of the puerperal uterus, and even in large doses is free from undesirable side effects - again a feature which distinguishes it from the other ergot alkaloids previously known. Finally, the possibility of producing peripheral gangrene by its repeated use is apparently non-existent."

With regard to its medical use he added ${ }^{5}$ :

"... the chief use of ergometrine is in the prevention and treatment of post-partum haemorrhage. Here the ergometrine effect is seen at its best. If after the delivery of the placenta the uterus is unduly relaxed, the administration of ergometrine, $1 \mathrm{mg}$ by mouth or 0.5 $\mathrm{mg}$ by injection, will quickly cause a firm contraction of the organ. If severe haemorrhage has already set in, it is strongly recommended that the drug should be given by the intravenous route. For this purpose one-third of the standard size ampoule may be injected or, for those who wish accurate dosage, a special ampoule containing $0.125 \mathrm{mg}$ is manufactured. An effect may be looked for in less than one minute."

Many years later Moir reminisced on his discovery at University College Hospital. ${ }^{6}$

\begin{abstract}
"As a recent-comer to the hospital I had sensed the need for caution in conducting clinical research. I knew that I had the support of my chief and of other senior members of the staff, but in some other quarters there was undoubtedly an atmosphere of suspicion which sometimes even approached hostility. This opposition I largely overcame by placing my recording gear out of sight in a small room adjacent to the ward. From this room a permanent communication had been established with the ward by means of a length of thin gas-piping which I had quietly placed between two convenient windows. I pray that the hospital authorities have now forgiven this secret injury to their fitments.
\end{abstract}

"Financial resources at that time were also slim; and it is perhaps my Scottish inheritance which makes me fill with pleasure when I recall that the cost of the enterprise was negligible. One shilling was used for the lead piping and five shillings for the purchase of an alarm clock which, fitted with electrical contacts and used in conjunction with the mechanism of a worn-out electric bell, enabled me to add minute-markings to the kymograph charts. These and other contrivances were all improvised from discarded hospital material. Only the clockwork-moving drum was specially requisitioned, and it was already part of the departmental equipment. The claim can thus be made that the discovery of the presence of the new ergot principle . . . was accomplished at total cost of six shillings."

On the events on 11 March 1932 he added ${ }^{6}$ :

"In the adjacent side-room I watched, rather sceptically, the movement of the recording needle. First a few meaningless excursions; then with startling suddenness the needle rose (fig 2: top). Up and up it went until the movement resolved itself into vigorous and sustained oscillations. This was activity of a different order and different quality from any I had previously witnessed . . . Leaving my work, and with a mind still full of wonder, I made my way home. I had seen the uterus behave in an unprecedented fashion. I had seen it contract with startling suddenness, and I had seen it contract, not after parenteral injection, but after the administration of a crude ergot extract by mouth. While thus lost in thought there flashed on me the true meaning of Dr. John Stearns's words. The events of the day were now crystal-clear. I had stumbled on the long-forgotten 'Dr. John Stearns's effect'."

In 1937 Moir was appointed first holder of the Nuffield chair of obstetrics and gynaecology, University of Oxford, a position he held until his retirement 30 years later. During the same period he was a fellow of Oriel College. He soon built up a thriving department of obstetrics and gynaecology at the Radcliffe Infirmary. Although the emphasis was on research, during the war he also took on responsibility for undergraduate teaching and the care of expectant mothers evacuated from London. Moir became examiner in obstetrics and gynaecology for the University of Oxford and for the RCOG, where 
he also served as counsellor and ambassador. He was much in demand as a speaker both at home and abroad, particularly in North America. For several years he was co-editor of MunroeKerr's Operative obstetrics and sole editor of the 7th edition (1964). ${ }^{12}$

Many honours came Moir's way. ${ }^{2}$ He became president of the obstetrics and gynaecology section of the Royal Society of Medicine and in 1974 was made an honorary fellow of both that Society and of Oriel College. He was an honorary DSc of Edinburgh and Manchester Universities, and DM of the University of Oxford. He was also made an honorary fellow of the American Association of Obsetricians and Gynecologists, and of the New York Academy of Medicine, an honorary LLD of Queens University, Ontario, and was appointed Master of Midwifery by the Society of Apothecaries, London. In 1961 he was appointed CBE. After his retirement in 1967, Moir returned to the Hammersmith as visiting professor to continue his outstanding work on the repair of vesicovaginal fistulae. His classic book on this subject, first published in 1961, became the standard text.

In 1933 Moir had married Grace Hilda Bailey. She was a great support and they had two sons and two daughters. On 24 November 1977 Moir died at his home, 22 Chalbury Road, Oxford. He was 77 years old. The obituary in The Times described him as: "a kindly, courteous and sensitive man who was both a dreamer and a doer. Tall, slim, aesthetic, never robust-looking yet wiry and tenacious, he knew his own mind and could be strong in battle, as well as generous and considerate to those in opposition. A loyal friend, he loved his family, home, profession and garden, his native hills and the customs and dialects of the folk of Angus". ${ }^{1}$ So passed one of the most distinguished and best loved men in obstetrics and gynaecology in Britain during the 20th century, a man who saved countless lives from obstetric haemorrhage and made the lives of many more women bearable through the repair of their vesicovaginal fistulae.

\section{REFERENCES}

1 Obituary: Professor Chassar Moir. The Times 1977 Nov 26.

2 Obituary: J Chassar Moir. BM 1977;ii: 1551.

3 Moir $C$. The action of ergot preparations on the puerperal uterus. BMW 1932; ii: $1119-22$

4 Dudley HW, Moir C. The substance responsible for the traditional clinical effect of ergot. BM 1935;i:520-3.

5 Moir C. Clinical experiences with the new alkaloid, ergometrine. BM 1936;ii:799-801.

6 Moir JC. The obstetrician bids, and the uterus contracts. BM 1964; ii: 1025-9. 